\title{
JUVENTUDE, EDUCAÇÃO, VIOLÊNCIA E PERSPECTIVAS DE FUTURO
}

\author{
YOUTH, EDUCATION, VIOLENCE \\ AND FUTURE PERSPECTIVES
}

A temática objeto de reflexão dos diferentes artigos que compõem o presente dossiê, Juventude, educação, violência e perspectivas de futuro, tem mobilizado diferentes setores da sociedade no sentido de pensar a respeito de alternativas que contemplem as angústias e expectativas de jovens e adolescentes de diferentes classes sociais, mas principalmente daqueles desprovidos de oportunidades de inserção social e profissional.

$\mathrm{O}$ contexto de incertezas que acompanha o cotidiano de jovens e adolescentes, tendo em vista as questões econômicas, sociais e psicológicas características da sociedade atual como apontam diferentes autores nacionais e internacionais (CASTEL, 1997; SALES; ADAM; FONSECA, 2014; ZALUAR, 1997), obriga-nos a refletir a partir de diferentes perspectivas, a fim de entendermos os jovens e de buscarmos respostas e caminhos para auxiliá-los nessa trajetória de pensar o futuro a partir das condições concretas de vida, como apontam autores como Sposito (2017) e Feixa \& Lecardi(2010). Questões como conflitos, violências e injustiças que atravessam o cotidiano escolar e social dos jovens têm interferido nos processos de subjetivação e constituição identitária, bem como nas possibilidades de inserção social e profissional diante da precarização da formação e do trabalho, do individualismo, da mudança rápida da tecnologia e da dificuldade concreta de realizar um projeto de vida e profissional. Nesse contexto, a pergunta que perpassa todos os textos e é em que medida o processo educacional, suas políticas e diferentes espaços e propostas podem dar resposta a essas inquietações.

Nesse sentido, os artigos apresentados buscam refletir sobre tais inquietações, trazendo diferentes abordagens e desvelando aspectos relacionados a imaginários, identidades, teorias e práticas sobre a juventude e o seu modo de se constituir e estar na sociedade, bem como as perspectivas possíveis e as limitações para inserção social e profissional no quadro da sociedade atual.

Assim, primeiramente, são apresentados os artigos que se propõem a analisar e discutir o modo como a juventude tem sido conceituada nos documentos oficiais e nas relações cotidianas das escolas. Tais artigos apresentam como esses jovens, de ambos os sexos, apreendem suas vivências, além dos modos como a educação e, mais especificamente, a instituição escola tem atuado.

A seguir, são apresentados os artigos que analisam e problematizam a expectativa de futuro para os jovens, em seu aspecto profissional e de convivência social, a partir das realidades concretas de vida, as quais muitas vezes são permeadas por relações violentas, sejam mediadas pelas redes sociais ou pela (im)possibilidade de um futuro planejado.

O primeiro artigo, de Maria Cecília Luiz, Nádia Perez Pino, Clarissa Bengtson e Douglas Pino, analisa o discurso da Secretaria de Educação do Estado de São Paulo (SEESP) sobre juventude, bem como o conceito de protagonismo juvenil nesse contexto. Ao analisar os discursos da SEESP sobre a juventude, o artigo destaca que a secretaria adotou, em princípio, novas práticas discursivas sobre os jovens, até então caracterizados pela situação de vulnerabilidade e de risco, com potencialidade para atos violentos. Assim sendo, na primeira seção do artigo, os autores sintetizam as atuais políticas da SEESP dentro do contexto das políticas educativas, apresentando as tendências e orientações da secretaria nos últimos anos, especialmente no que se refere aos programas direcionados aos jovens. Posteriormente, os autores discutem as ações da SEESP direcionadas ao protagonismo juvenil e seus diferentes programas, problematizando a ideia do novo a partir das próprias políticas da secretaria e buscando entender os intuitos democratizantes presentes nesse 
discurso.

O segundo artigo, de Elisiane Spencer Quevedo Goethel, Caroline Polido e Débora Cristina Fonseca, tem como objetivo discutir a judicialização das relações escolares e os aspectos punitivos e educativos das ações tomadas pela escola. Para tanto, foram analisados processos judiciais de alunos do Ensino Fundamental II que tiveram sua origem por iniciativa da escola. Trata-se de uma pesquisa documental de análise qualitativa, na qual foi utilizada a análise de conteúdo como metodologia. $O$ estudo aponta que as situações de violência ocorridas no âmbito da escola estão sendo direcionadas para o sistema de justiça na tentativa de que o conflito seja afastado e resolvido fora da escola.

O terceiro artigo, de Alice Miriam Happ Botler, tem por objetivo analisar a relação entre juventude e escola, com foco no sentimento de injustiça resultante de toda sorte de conflitos ali presentes. Com o intuito de melhor compreender essa relação, bem como de alertar para práticas sociais visando à redução das violências e demais conflitos nas escolas, o ensaio apresenta recorte de pesquisa qualitativa, trazendo estudos de casos com escolares de Brasil e Portugal, por meio dos quais a autora analisa concepções e reações de estudantes de Ensino Médio diante das tensões entre as demandas individuais e as sociais, com ênfase nos princípios de justiça. A pesquisa fundamenta-se teoricamente em conceitos como juventudes, democracia e justiça. Entre as considerações assumidas a partir dos dados apresentados, reforça-se a tese de que a escola é um lugar propício para resolver conflitos de maneira não violenta, por meio da sensibilização e da transformação, mas é destacado que parece haver um hiato para tal realização, pelo fato de que a fundamentação nos princípios básicos da justiça, como comunicação não violenta, empatia e respeito, tem encontrado entraves nas relações do cotidiano da escola.

O quarto artigo, de Liliane Pereira de Souza, apresenta o resultado de uma pesquisa que discute o que jovens e adolescentes do Ensino Médio pensam, sentem e avaliam sobre violência e não violência, utilizando imagens e fotografias produzidas por eles. A pesquisa foi realizada na cidade de Campo Grande, capital do estado do Mato Grosso do Sul. Além da pesquisa bibliográfica, a autora utilizou metodologias como a História Oral e o Photovoice, além de Grupo Focal, entrevistas individuais e questionários. Para as análises, o método foi o mesmo usado por Roland Barthes no livro A Câmara Clara. As fotografias foram organizadas por eixos temáticos pelos jovens colaboradores da pesquisa, sendo elas as imagens mais significativas por eles escolhidas. $\mathrm{O}$ artigo apresenta, também, as análises narrativas das fotografias feitas durante as sessões de Grupo Focal. Os resultados mostraram a compreensão sobre as diversas manifestações de violências e os desafios enfrentados, bem como as sugestões e propostas para lidar com esse fenômeno.

O quinto artigo, de Concepción Fernández Villanueva e Joyce Mary Adam, aborda as diferenças de gênero na violência escolar a partir de uma perspectiva interacionista, que considera as posições de poder dos agressores e das vítimas, bem como os fatores que afetam as situações de conflito e os processos de explicação e representação dos atos de violência. $\mathrm{O}$ artigo se refere a um estudo que analisou incidentes de violência ocorridos em duas escolas da periferia de uma cidade do interior do estado de São Paulo, a partir de entrevistas em grupo com jovens escolares de ambos os sexos. Embora a pesquisa tenha encontrado protagonismos de violência tanto de meninas como de meninos, a conclusão foi que essas são menos protagonistas e mais vítimas que os meninos, além de que os argumentos explicativos da violência são semelhantes entre meninos e meninas, embora os homens destaquem a rivalidade contra a escola e as mulheres, a rivalidade interpessoal.

O sexto artigo, de Émile-Henry Riard, discute a questão do projeto de vida como forma de reorganização e construção identitária, constituindo resposta às inquietações dos jovens e adolescentes e trabalhando os aspectos vinculados tanto à realidade concreta quanto ao imaginário criado por eles. Destacam-se os projetos de vida e profissional como ferramentas para a construção da futura vida profissional e privada dos adolescentes, afirmando que tais projetos variam de acordo com o contexto social. Assim, o autor indaga sobre o lugar concreto e modo como esses se constituem nos diferentes contextos. Indaga-se ainda quão participativos jovens e adolescentes são da construção do projeto de vida, bem como que espaço eles deixam para seus desejos, questionando o quanto os adolescentes podem expressar-se "livremente", ser reduzidos a meros expectadores ou ignorados em benefício das demandas da sociedade. Outro questionamento que o autor apresenta refere-se a qual é o lugar da família, da escola e das associações nesse processo.

O sétimo artigo, de Luciano Plez de Melo e Leila Maria Ferreira Salles, discute a temática sobre juventude e escola, ao propor uma reflexão sobre juventude, escola e construção de projetos de vida. A referência para essa reflexão são os jovens moradores de periferias urbanas empobrecidas, pertencentes aos extratos sociais 
mais desfavorecidos da população, e as escolas que frequentam. Em geral, são jovens cujo lugar que lhes é reservado é o subemprego ou de trabalhador temporário portador de uma escolarização considerada de baixa qualidade. Diante dessas suposições, os autores trazem uma indagação sobre o que tem possibilitado ou contribuído para que a escola perca uma de suas marcas identitárias: contribuir para a construção de projetos de vida ou de perspectiva de futuro. A hipótese levantada, sobre a qual os autores se pautam, é a discussão sobre o fato de o espaço escolar comutar-se e confundir-se, mesmo parcialmente, em rua ou em espaço de lazer, transformando-se em local de gozo ou de prazer, concomitantemente ao fato de os certificados escolares tenderem a perder seu valor, perdendo sua especificidade historicamente construída e impossibilitando ou dificultando a ação da escola como mediadora dos projetos de vida.

O oitavo artigo, de Tânia Maria Rechia Schroeder e Claudia Barcelos de Moura Abreu, apresenta reflexões sobre comentários de internautas a respeito de jovens e seus envolvimentos com violência na cidade de Cascavel (PR). Trata-se de uma pesquisa etnográfica virtual cuja estratégia metodológica está ancorada nos fundamentos epistemológicos da sociologia do cotidiano de Michel Maffesoli em Elogio da Razão Sensível (1998), bem como no conceito de violência antropológica de René Girard em A Violência e o Sagrado (1990). Discutem-se o reforço dos estereótipos e a construção de um imaginário social a respeito de jovens que se expressa por meio de um sentimento de insegurança, como se representassem uma ameaça maior do que aquela que os dados estatísticos demonstram.

O conjunto das discussões presentes nos diferentes artigos contribui para que diferentes abordagens, sejam elas sociológicas, psicológicas ou históricas, debrucem-se sobre a complexa problemática da juventude, que, antes de ser um processo a ser considerado unicamente pela individualidade dos sujeitos, joga luz sobre a subjetividade construída a partir do contexto de vida e da perspectiva de futuro possível.

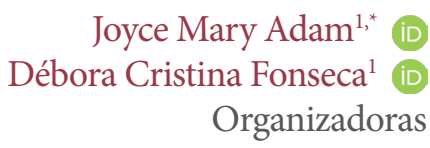

\section{REFERÊNCIAS}

CASTEL, R. A dinâmica dos processos de marginalização: da vulnerabilidade à desfiliação. Cadernos CRH. UFBa, 10(26), 1997. Disponível em portalseer.ufba.br.

FEIXA, C.; LECCARDI, C. O conceito de geração nas teorias sobre juventude. Revista Sociedade e Estado. Brasília, 25(2), p. 185-204, 2010. Disponível em <http://www.scielo.br/scielo.php?script=sci_ arttext\&pid=S0102 69922010000200003\&lng=en\&nrm=iso >

SALLES, L.M.F.; ADAM, J.M.; FONSECA, D. Violência e inserção social do jovem de periferia urbana. Revista Psicologia: Teoria e Prática, São Paulo, 16(3), 58-68. 2014. https://doi.org/10.15348/1980-6906/psicologia. v16n3p58-68

SPOSITO, M.P.; TARABOLA, F.de S. Entre luzes e sombras: o passado imediato e o futuro possível da pesquisa em juventude no Brasil. Rev. Bras. Educ., Rio de Janeiro, 22(71), e227146, 2017.

ZALUAR, A. Exclusão e políticas públicas: Dilemas teóricos e alternativas políticas. Revista Brasileira de Ciências Sociais. São Paulo, 12(35), 1997.

\footnotetext{
1.Universidade Estadual Paulista Júlio de Mesquita Filho - Instituto de Biociências - Departamento de Educação - Rio Claro (SP), Brasil. E-mails: joyce.adam@unesp.br, debora.fonseca@unesp.br

*Autora correspondente: joyce.adam@unesp.br

Comitê Editorial do Cedes/Coordenação deste número: Izabel Galvão e Maria Rosa Camargo
}

Deixamos aqui nossa homenagem a Profa. Dra. Leila Maria Ferreira Salles, autora de um dos artigos, que faleceu durante a edição deste número do Cadernos do Cedes. A profa. Leila sempre teve em suas preocupações a temática da adolescência e juventude, violências e escola. Construiu uma consistente e profícua vida acadêmica e certamente deixa um legado sobre o tema, além de muitas saudades entre aqueles que tiveram a oportunidade e o privilégio de conviver com ela, principalmente os membros do grupo de pesquisa JOVEDUC e os colegas do Departamento de Educação da Unesp de Rio Claro. Uma colega muito querida e companheira de pesquisas. 